\title{
Inhaled corticosteroids reduce neutrophilic bronchial inflammation in patients with chronic obstructive pulmonary disease
}

\author{
Marco Confalonieri, Elsa Mainardi, Rossana Della Porta, Sergio Bernorio, \\ Luciano Gandola, Bianca Beghè, Antonio Spanevello
}

\begin{abstract}
Background-Airways inflammation is a feature of chronic obstructive pulmonary disease (COPD), but the role of corticosteroids in the management of clinically stable patients has yet to be established. A randomised controlled study was carried out to investigate the effect of high dose inhaled beclomethasone dipropionate (BDP) administered for two months to patients with stable, smoking related COPD. Sputum induction was used to evaluate bronchial inflammation response.
\end{abstract}

Methods-34 patients (20 men and 14 women) were examined on three separate occasions. At the initial clinical assessment (visit 0 ), spirometry and blood gas analysis were performed. On visit 1 (within one week of visit 0 ) sputum induction was performed and each patient was randomised to receive either BDP $500 \mu \mathrm{g}$ three times daily (treated group) or nothing (control group). After two months (visit 2), all patients underwent repeat clinical assessment, spirometry, and sputum induction.

Results-There were no differences in sputum cell counts between the groups at baseline. After two months of treatment, induced sputum samples from patients in the treated group showed a reduction in both neutrophils $(-27 \%)$ and total cells $(-42 \%)$ with respect to baseline, while the control group did not (neutrophils $+9 \%$, total cells $+7 \%)$. Macrophages increased in the treated group but not in the control group. The mean final value of sputum neutrophils was $52 \%$ in the treated group and $73.3 \%$ in the control group (95\% confidence interval (CI) -27.2 to -15.4$)$. The mean final value of sputum macrophages was $35.8 \%$ in treated group and $19.3 \%$ in control group (95\% CI 10.3 to 22.8 ). The differences between the treated and control groups for neutrophils $(-21.3 \%)$, macrophages $(+16.5 \%)$, and total cells $(-65 \%)$ were significant. Spirometry and blood gas data did not change from baseline in either patient group.
Conclusions-A two month course of treatment with high dose inhaled BDP reduces significantly neutrophil cell counts in patients with clinically stable, smoking related COPD. Further studies on the effectiveness of inhaled steroids in COPD are needed to confirm the clinical importance of this observation.

(Thorax 1998;53:583-585)

Keywords: chronic obstructive pulmonary disease; neutrophils; beclomethasone dipropionate; induced sputum analysis

The value of corticosteroids in the management of clinically stable chronic obstructive pulmonary disease (COPD) has yet to be established. ${ }^{12}$ In particular, there is very little evidence to date on the effect of inhaled steroids in this disease. ${ }^{34}$

Our study aimed to evaluate, using sputum induction, ${ }^{5}$ the effects of two months of inhaled high dose $(1500 \mu \mathrm{g} /$ day $)$ beclomethasone dipropionate (BDP) on bronchial inflammation in patients with stable, mild to moderate COPD related to smoking.

\section{Methods}

SUBJECTS

We recruited 34 patients (20 men and 14 women, aged 53 to 71 years) with stable COPD from the outpatient clinic of the Crema Hospital. Clinically stable COPD was diagnosed according to a recent European consensus conference. ${ }^{6}$ Patients were smokers who refused or failed a programme to quit smoking. During the course of the study, the subjects were asked to continue smoking the same number of cigarettes each day as at the time of

Table 1 Characteristics of COPD patients at baseline

\begin{tabular}{lll}
\hline & Treated group & Control group \\
\hline Sex (M/F) & $11 / 6$ & $9 / 8$ \\
Age (years) & $58(6)$ & $57(4)$ \\
Smoking (packs/year) & $50(7)$ & $48(8)$ \\
FEV $_{1}$ (\% predicted) & $60.2(9)$ & $59.1(9)$ \\
$\mathrm{FEV}_{1} / \mathrm{VC}(\%)$ & $68(3)$ & $65(6)$ \\
$\mathrm{PaO}_{2}(\mathrm{~mm} \mathrm{Hg})$ & $71.9(5.8)$ & $69.7(3.8)$ \\
$\mathrm{PaCO}_{2}(\mathrm{~mm} \mathrm{Hg})$ & $39.2(3.5)$ & $38.6(5.2)$
\end{tabular}

Data are presented as mean (SE). 
Table 2 Induced sputum cellularity results, spirometric data, and blood gas analysis in the BDP treated patients and controls

\begin{tabular}{|c|c|c|c|c|}
\hline & \multicolumn{2}{|l|}{$B D P$} & \multicolumn{2}{|l|}{ Controls } \\
\hline & Before & After & Before & After \\
\hline Cells $/ \mathrm{ml}\left(\times 10^{4}\right)$ & $240(46)$ & $139(63)$ & $198(31)$ & $204(39)$ \\
\hline Neutrophils (\%) & $73.4(2.6)$ & $52.0(1.8)$ & $71.4(3.7)$ & $73.3(2.2)$ \\
\hline Eosinophils (\%) & $3.5(1.0)$ & $3.1(0.8)$ & $2.0(0.4)$ & $2.4(0.5)$ \\
\hline Lymphocytes (\%) & $3.8(0.8)$ & $3.9(0.7)$ & $2.0(0.2)$ & $2.2(0.9)$ \\
\hline Macrophages (\%) & $19.6(1.9)$ & $35.8(2.1)$ & $21.7(3.6)$ & $19.3(2.2)$ \\
\hline Epithelial cells (\%) & $1.1(0.1)$ & $2.3(0.3)$ & $1.5(0.2)$ & $2.0(0.3)$ \\
\hline Viability (\%) & $84(5)$ & $81(8)$ & $79(8)$ & $86(5)$ \\
\hline Squamous cells (\%) & $7(1)$ & $8(2)$ & $9(2)$ & $6(3)$ \\
\hline $\mathrm{FEV}_{1}(\%$ predicted) & $60.2(9)$ & $58.2(10)$ & $59.1(9)$ & $54.4(8)$ \\
\hline FVC (\% predicted) & $76(12)$ & $74(14)$ & $83(7)$ & $76(9)$ \\
\hline $\mathrm{PaO}_{2}(\mathrm{~mm} \mathrm{Hg})$ & $71.9(5.8)$ & $75.0(6.2)$ & $69.7(3.8)$ & $70.3(4.3)$ \\
\hline $\mathrm{PaCO}_{2}(\mathrm{~mm} \mathrm{Hg})$ & $39.2(3.5)$ & $36.8(3.9)$ & $38.6(5.2)$ & $37.3(3.2)$ \\
\hline
\end{tabular}

Values are mean (SE).

entry. Patients who had taken inhaled or oral steroids or had suffered a respiratory tract infection in the previous three months were excluded. None of the patients was taking theophyllines, or oral or long acting inhaled $\beta_{2}$ agonists. All subjects gave written informed consent to participate in the study, which was approved by the local ethics committee. We compared sputum cell counts of COPD patients with those of 16 healthy non-atopic volunteers, age matched with the subjects in the investigation. All the healthy subjects were asymptomatic lifelong non-smokers with normal spirometry.

STUDY DESIGN

The study was a randomised, controlled, open study. The clinical part of the study was open, but all differential cell counting was carried out in a double blind fashion. Subjects were examined on three separate days. At the initial clinical assessment (visit 0), spirometry plus formal testing for reversibility, and blood gas analysis were performed. At visit 1 (within one week of visit 0 ) each patient was randomised to receive either BDP $500 \mu \mathrm{g}$ three times daily (treated group) or no treatment (control group). Sputum induction was also carried out. All patients were reviewed after eight weeks for repeat clinical assessment, spirometry, blood gas analysis, and sputum induction (visit 2).

SPUTUM INDUCTION

Inhalation procedure

Forced expiratory volume in one second $\left(\mathrm{FEV}_{1}\right)$ and forced vital capacity (FVC) were measured before and 10 minutes after inhaled salbutamol (two puffs; $200 \mu \mathrm{g}$ ). Subjects then inhaled hypertonic $(4.5 \%)$ saline nebulised by an ultrasonic device (De Vilbiss 65, DeVilbiss Corporation, Somerset, Pennsylvania, USA) for increasing time periods-one, two, four, eight, and 16 minutes. $\mathrm{FEV}_{1}$ measurements were repeatedly taken one minute after each inhalation period.

\section{Sputum processing}

Sputum samples were examined within two hours. Sputum quality was assessed, selected portions of the sputum sample were chosen, total cell counts were performed, and cytospins prepared using previously described methods. ${ }^{7}$ Samples were discarded if viability levels were $50 \%$ or less, or squamous contamination was $20 \%$ or more, or both. An overall differential cell count on 500 nucleated non-squamous cells was performed by two examiners and results reported as mean of the two counts. All sputum counts and measurements were performed blind to the clinical details.

\section{DATA ANALYSIS}

Group data were expressed as mean (SE). Between group changes in cell counts were compared with the Mann-Whitney U test and a 95\% confidence interval (CI). Between group differences, with regard to blood gas and spirometry data, were subjected to unpaired $t$ test. Statistical significance was defined as $\mathrm{p}<0.05$.

\section{Results}

There were no significant differences between the treated and control groups of the COPD patients with regard to age, smoking history, blood gas, and spirometry (table 1). None of the COPD patients was unable to produce adequate sputum samples or stopped the procedure because of a fall in $\mathrm{FEV}_{1}$ or worsening of symptoms. The coefficient of variability of duplicate counts was less than $6 \%$ with a degree of correlation greater than 0.8 . The percentage of neutrophils in the sputum of the COPD patients was significantly higher than in the healthy subjects' sputum (treated group 73 (3); control group 71 (4); healthy subjects 29 $(18) ; \mathrm{p}<0.05)$. There was no difference in the sputum cell counts at baseline between the treated and control groups of the COPD patients (table 2).

After two months of treatment with BDP, induced sputum samples from the treated patients showed a reduction from baseline of both neutrophils (fig 1) and total cells (table 2).

Table 3 Sputum cell counts for treatment and placebo groups, and difference between the groups at visit 2

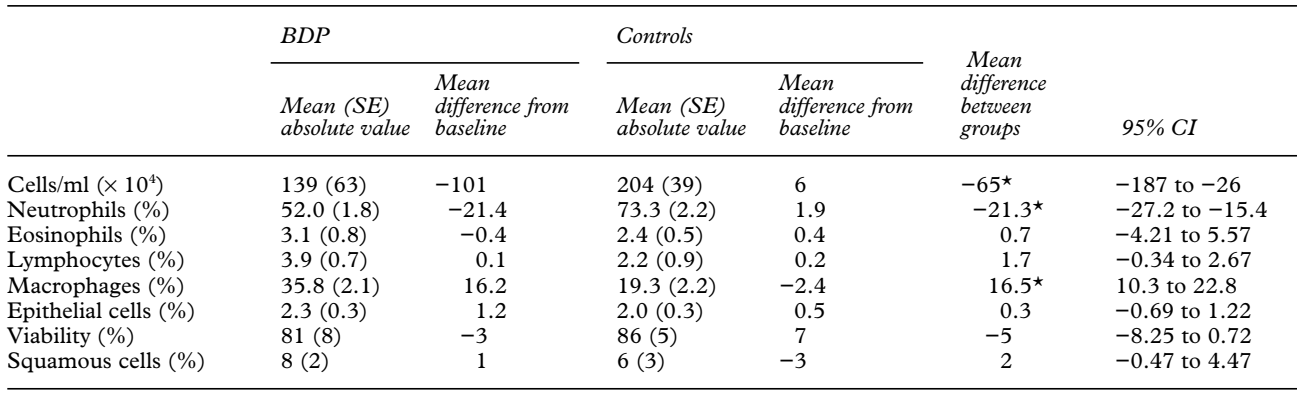

${ }^{\star} \mathrm{p}<0.05$. 


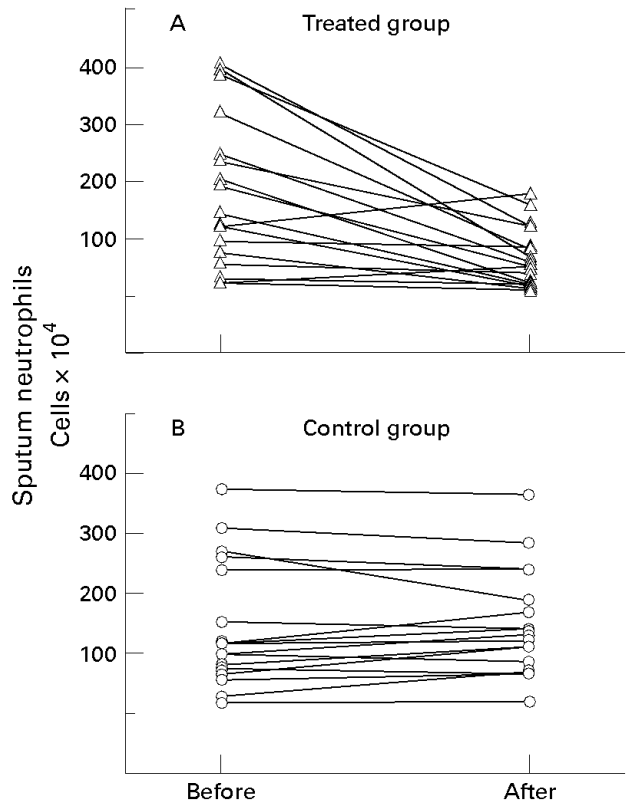

Figure 1 Sputum total neutrophil counts before and after two months of treatment with inhaled steroid (beclomethasone dipropionate) (A) or no treatment (B). Between group comparison of neutrophil counts was significantly different $(p<0.05)$.

There was little difference in total and differential cell counts in the control group at the end of the study compared to baseline values. Sputum macrophages increased only in the treated group (table 2).

The mean final value of sputum neutrophils was $52.0 \%$ in the treated group and $73.3 \%$ in control group (95\% CI -27.2 to -15.4$)$. The mean final value of sputum macrophages was $35.8 \%$ in the treated group and $19.3 \%$ in the control group (95\% CI 10.3 to 22.8 ). At the end of the study the differences between the treated and control groups for neutrophils $(-21.3 \%)$, macrophages $(+16.5 \%)$, and total cells $(-65 \%)$ were significant $(\mathrm{p}<0.05)$ (table 3).

$\mathrm{FEV}_{1}, \mathrm{FVC}, \mathrm{PaO}_{2}$, and $\mathrm{PaCO}_{2}$ did not change from baseline in either group (table 2).

\section{Discussion}

Our study aimed to evaluate, by sputum induction, the effect of two months of inhaled high dose BDP $(1500 \mu \mathrm{g} /$ day $)$ on bronchial inflammation in stable patients with COPD. We found that the proportion of neutrophils and the number of neutrophils present in induced sputum samples decreased over two months in patients receiving the high dose of inhaled BDP. Our findings are supported by Llewellyn Jones et al who also treated COPD subjects with inhaled steroids (in a double blind manner) for several months. ${ }^{3}$ That study showed a small but significant reduction in the chemotactic activity of the secretions which would be consistent with a decrease in subsequent neutrophil recruitment.

Keating et al, however, found no significant anti-inflammatory effect of inhaled steroids in COPD patients treated over two weeks. ${ }^{4}$ It is highly likely that a longer period of treatment is important in a condition such as COPD, which has low grade inflammation, rather than a more acute disease like asthma. ${ }^{8}$ In our study inhaled BDP did not change the results of lung function tests and this is consistent with the patient population being studied. Renkema et al showed that budesonide $1600 \mu \mathrm{g}$ daily slowed down the rate of lung function decline in patients with stable COPD during two years of treatment. ${ }^{9}$ This suggests that a reduction in airway inflammation might influence lung function decline only over a long period of treatment with inhaled corticosteroids. This hypothesis is supported by Stanescu et al who evaluated induced sputum cellularity in smokers over 15 years. ${ }^{10}$ They showed that airways obstruction and chronic expectoration, as well as accelerated decline in lung function, are associated with increased number of neutrophils in the sputum.

In summary, our results support the hypothesis that inhaled steroids might be beneficial in treating stable COPD, leading to a decrease in bronchial neutrophilic inflammation. Further double blind, placebo controlled studies are needed to confirm our observations.

1 Van Schayck CP, Van Grunsven PM, Dekhuijzen PN. Do patients with COPD benefit from treatment with inhaled corticosteroids? [editorial]. Eur Respir f 1996;9:1969-70.

2 De Guia TS. Inhaled corticosteroids in COPD. A light at the end of the tunnel? [editorial]. Chest 1995;108:1486-7.

3 Llewellyn Jones CG, Harris TAJ, Stockley RA. Effect of fluticasone propionate on sputum of patients with chronic bronchitis and emphysema. Am $\mathcal{F}$ Respir Crit Care Med 1996;153:616-21.

4 Keatings VM, Jatakanon A, Worsdell YM, et al. Effects of inhaled corticosteroids on inflammatory indices in asthma and COPD. Am f Respir Crit Care Med 1997;155:542-8.

5 Pavord ID, Pizzichini MMM, Pizzichini E, et al. The use of Pavord ID, Pizzichini MMM, Pizzichini E, et al. The use of
induced sputum to investigate airway inflammation. Thorax induced sputum to

6 Siafakas NM, Vermeire P, Pride NB, et al. Optimal assessment and management of chronic obstructive pulmonary disease (COPD). Eur Respir f 1995;8:1398420 .

7 Spanevello A, Migliori GB, Sharara AM, et al. Induced sputum to assess airway inflammation: a study of reproducibility. Clin Exp Allergy 1997;27:1138-44.

8 Chanez P, Vignola AM, O'Shaugnessy T, et al. Corticosteroid reversibility in COPD is related to features of asthma. Am $\mathcal{F}$ Respir Crit Care Med 1997;155:1529-34.

9 Renkema TEJ, Schouten JP, Koëter GH, et al. Effects of long-term treatment with corticosteroids in COPD. Chest 1996;109:1156-62.

10 Stanescu D, Sanna A, Veriter C, et al. Airways obstruction, chronic expectoration, and rapid decline of $\mathrm{FEV}_{1}$ in smokers are associated with increased levels of sputum neutrophils. Thorax 1996;51:267-71. 